\title{
More public support in prospect
}

THE British Government is to spend $£ 129$ million over the next six years in support for its home microelectronic component production industry. A new extension to the Microelectronics Industry Support Programme, MISP 2, more than doubles the finance previously available, which is now fully committed. The government's action is intended to spur industrial companies to invest $£ 1,000$ million in the development and production of integrated circuits during the rest of the decade.

Mr Kenneth Baker, Minister for Information Technology, said last week that Britain has now caught up with West Germany as the largest consumer of microchips in Western Europe. The increased consumption is ascribed in part to the success of the government's separate programme to encourage the use of microelectronics in industry. But now there is concern that Britain should not become reliant on overseas sources for specialized "custom" chips, and the new scheme is aimed especially at encouraging companies to invest in facilities for their development and production.

MISP 1 was worth $£ 55$ million and will

\section{Japanese space research}

\section{Shoestring programme prospers}

Tokyo

THE Japanese Government has given tentative approval to plans for scientific missions to the "Moon and planets" and, at a much later date, for exploration of Jupiter-type planets and asteroids in the final version of its new 15-year space development programme.

The programme is aimed chiefly at the development of a large rocket for the launch of telecommunication satellites by the National Space Development Agency of Japan (NASDA) (see Nature 1 March, p.3) but it also gives significant encouragement to the continued expansion of the Institute of Space and Astronautical Science (ISAS) - a unique academic body with its own satellites, rockets and launch sites.

Although the encouragement to ISAS from the government is most welcome, Professor Minoru Oda, its directorgeneral, is quick to point out that the programme has been deliberately worded in the most ambiguous manner possible. No definite plan has been approved, for there is a great debate within ISAS over which direction to take next.

Despite the apparent illogicality of having separate academic and commercial space programmes, ISAS has so far proved to be a highly successful organization. In the past six years, scientific satellites for the study of the magnetosphere, X-ray sources, solar flares and the middle atmosphere have been launched at the rate have stimulated investment worth $£ 270$ million. Its successor is designed to ensure that the growth of British production at least equals the world average. Home production of integrated circuits will be worth $£ 300$ million in 1985 , roughly a fivefold increase in real terms since 1978.

The new scheme recognizes the extremely high initial capital investment needed for semiconductor production. Grants of up to 25 per cent will be available for both high and low volume production projects and purchase of computer-aided design facilities. Grants of up to $£ 3,000$ will be made for feasibility studies.

There may also be some support for development projects if these do not overlap with the government-supported Alvey programme of research and development in information technology. Companies involved only indirectly in semiconductor production will be eligible for support for projects that are likely to improve the availability of materials, and a large part of the new programme will be spent in companies producing semiconductor manufacturing equipment.

Tim Beardsley

continue the successful X-ray astronomy series with the launch of ASTRO-D, a satellite which could complement the United States' planned Advanced X-ray Astronomy Facility (AXAF). Or the line of research begun with the solar flare observation satellite Hinotori could be continued with a new mission for the next solar maximum. Again, there is support for launching a satellite to act as a space outpost for the ground-based Very Long Baseline Interferometer (VLBI) now under construction in the United States.

The first decisions are expected in the next few months, for ISAS must soon decide whether to participate in yet another project - the building and launching of one of the four satellites necessary for the US Open Plasma Observation Network.

All these projects - even the launch of a lunar orbiter - are just within the capability of ISAS and its home-developed solid-fuel MU-3S series rockets. But a major question that will have to be answered soon is how long ISAS can keep going with the strange constraint - enforced by the government - that it should develop no rocket with a diameter greater than 1.4 metres. And if it should prove necessary for larger satellites to be launched by the more powerful NASDA rockets, would ISAS then lose some of its closelyguarded independence? Alun Anderson - As well as visiting Japan (Nature 15 March, p.216), Mr James Beggs, administrator of the US National Aeronautics and Space Administration (NASA) has been in Europe in search of partners for NASA's manned space station project. Beggs' proposals seemed to be attractive to the Japanese Government - after reassurances that Japanese technology would not be used in any military applications - although it is difficult to see where the money would come from. In Europe there was also a glimmer of hope for NASA. Speaking after the troubled European summit on 20 March, President Mitterrand said that the EEC heads of government had discussed a project that would involve talks with the United States on a manned space station, but added that it was too soon to forecast the outcome. f a lunar probe would be pr Another strong possibility would be to

\section{Japan expands}

\section{Tokyo}

JAPAN may soon have a little more territory - if not actual living space - in the Pacific Iwojima island chain, $1,100 \mathrm{~km}$ south of Tokyo. A massive under-sea volcanic eruption has been taking place some $150 \mathrm{~km}$ north of Iwojima $\left(26^{\circ} 7^{\prime} 42^{\prime \prime} \mathrm{N}, 141^{\circ} 7^{\prime}\right.$ $30^{\prime} \mathrm{E}$ ) since at least $8 \mathrm{March}$ - when an aircraft of the Maritime Self-Defense Force (MSDF) spotted the eruption - and now appears ready to form a new volcanic island.

At first, grey and yellow waters were seen pouring from a central spot some 20-70 metres in diameter, discolouring the sea in a plume more than $50 \mathrm{~km}$ long and $3 \mathrm{~km}$ wide - by far the biggest under-sea disturbance seen in recent times. Flights by MSDF aircraft are now reporting that more than a dozen reefs have broken surface and that rocks are being hurled into the air.

The area is close to the Marianas Trench and some $300 \mathrm{~km}$ from the scene of a 1978 eruption that lasted for three months. If a new island forms it will be Japan's fifth in the past 100 years - although only two of them remain. The most recent, Nishi No Shima Shinto, was created in 1973-74 and now has a total area of 200,000 square metres.
Alun Anderson 